Savunma Bilimleri Dergisi

The Journal of Defense Sciences

May1s/May 2018, Cilt/Volume 17, Sayi/Issue 1.

ISSN (Bas1l1) : 1303-6831 ISSN (Online): 2148-1776

\title{
Fiziksel Buhar Biriktirme Yöntemlerinden PVD ve JVD/DVD İnce Film Kaplamaların Karşılaştırılması ve DVD Kaplama Teknolojisinin Endüstriyel Uygulamaları Üzerine Kavramsal, Akademik ve Teorik Bir Analiz *
}

\author{
Ayhan AYTAÇ** ve Uğur MALAYOĞLU***
}

$\ddot{O} z$

Günümüzde ülkelerin etkili ve güçlü silahlara sahip olması savunma sanayindeki teknolojik gelişmeler ile iliş̧kilendirilmektedir. Bir ülkenin ulusal teknolojisi, öncelikle savunma sanayindeki gelişmişlikle ölçülmektedir. Endüstride, sürtünmeye maruz kalan, bu nedenle çalışmayan ve verimliliğini kaybeden sistemlerin iyileştirilmesi amacıyla PVD, CVD, JVD/DVD, Plazma ve Termal püskürtme teknikleri kullanılarak çeşitti kaplamaların yapıldı̆̆ı görülmektedir.

$B u$ çalışmanın amacı, yüzey mühendisliği uygulamalarında sıklıkla kullanılan fiziksel buhar biriktirme (PVD) yöntemi ile yapılan ince seramik film kaplamalar ile ülkemizde henüz uygulaması bulunmayan, ancak üstün yönleri bakımından kritik teknolojiler arasinda yer alan doğrudan buhar biriktirme (DVD) kaplama yönteminin temel farklılıklarına değinerek, JVD/DVD kaplama teknolojilerinin üstün teknolojik özelliklerine dikkat çekmektir. Çalışmada, her iki kaplama yöntemi kavramsal ve sistem özellikleri açısından incelenmiştir. Her iki yöntemin farkları ortaya konularak, geleceğin kaplama teknolojisi olarak gösterilen DVD yönteminin ülkemizde uygulanabilirliği araştırılmıştır.

Sonuç olarak, Doğrudan Buhar Biriktirme (DVD) tekniği ile; sürtünmeye, ıslya ve aşınmaya dayanıkll, yüksek hızlarda çalışan makine elemanlarına, alaşım ve bileşiklerin düzlemsel ya da eğrisel yüzeylerine üstün özelliklere sahip ince film kaplama yapilabilmektedir.

Anahtar Kelimeler: PVD, DVD, JVD, Seramik Kaplamalar.

\footnotetext{
* Bu makale, 25-26 Nisan 2013 tarihlerinde Ankara'da gerçekleştirilen 6. Mühendislik ve Teknoloji Sempozyumu adlı kongrede sözlü özet bildiri olarak sunulmuştur.

** Öğretim Görevlisi, Millî Savunma Üniversitesi, Kara Harp Okulu Dekanlığı, Makina Mühendisliği Bölümü, Ankara, aytac@kho.edu.tr

*** Öğretim Üyesi, Dokuz Eylül Üniversitesi, Metalurji ve Malzeme Müğhendisliği Bölümü, İzmir, ugur.malayoglu@deu.edu.tr
} 


\title{
Comparison of PVD and JVD / DVD Thin Film Coatings by Physical Vapor Deposition Methods and a Conceptual, Academic and Theoretical Analysis on Industrial Applications of DVD Coating Technology
}

\begin{abstract}
Today, the fact that countries have effective and powerful weapons is directly related with technological developments in the defense industry. The national technology of an individual country is primarily measured by the development of the defense industry. Various coatings have been made using PVD, CVD, JVD/DVD, Plasma and Thermal spraying techniques in order to improve the quality of the systems which are exposed to friction, and so do not work, mostly results in loss of productivity in the industry.

The aim of this study is to describe the basic differences of the direct vapor deposition (DVD) coating method, which is not yet implemented but is among the critical technologies in our country. Application of thin ceramic film coatings made by physical vapor deposition (PVD) method is frequently used in surface engineering applications where attention is paid on the superior technological features of the coating technologies. In this study, both coating methods were examined in terms of conceptual and system properties. By demonstrating the differences between the two methods, the applicability of the DVD method, which is shown as the coating technology of the future, has been investigated in our country.

As a result, with the direct vapor deposition (DVD) technique; thin film coatings with superior properties effective on planar or curvilinear surfaces of alloys and compounds can be made on machine parts operating at high speed and therefore are expected to resist friction, abrasion and heat effects.
\end{abstract}

Keywords: PVD, DVD, JVD, Ceramic Coatings. 
Fiziksel Buhar Biriktirme Yöntemlerinden PVD ve JVD/DVD İnce Film

Kaplamaların Karşılaştırılması ve DVD Kaplama Teknolojisinin Endüstriyel

Uygulamaları Üzerine Kavramsal, Akademik ve Teorik Bir Analiz

\section{Giriş}

Yüzey mühendisliğinin amacı; belirli endüstriyel uygulamalar için en ekonomik ve optimum yüzey özellik tasarımlarını sağlayacak uygun teknolojilerin ortaya konmasını sağlamaktır. Fiziksel Buhar Biriktirme (PVD) yöntemleri kullanılarak üretilen ince seramik film kaplamalar, malzemenin aşınmaya karşı dayanımını yükselten etkili bir yöntem olmasının yanısıra uygun kaplama parametreleri seçildiğinde taban malzemenin kullanım ömrünü ve ticari değerini önemli ölçüde etkilemektedir (Huang vd., 2003:7-14).

Özellikle uzay ve havacılık sektörlerinin öncülüğünde, teknolojinin gelişimine paralel olarak yeni tasarım malzemelerde üstün mekaniksel özellikler aranır hale gelmiştir. İnşaat sektöründeki kaplama malzemesi kullanımının artmasına benzer biçimde makine ve imalat sanayinde de istenilen ürün özellikleri ekonomik bir biçimde sadece kaplama işlemi ile sağlanabilmektedir. Kaplama yöntemleri, kaplama malzemesinin bulunduğu fiziksel hale göre temel olarak; gaz halden, çözeltiden, sıvı veya yarı sıvı halden yapılan kaplamalar olmak üzere üç ana başlık altında incelenebilir. Bu başlıklar ve spesifik özelliklerine göre gruplandırılabilen alt başlıklar Şekil 1'de gösterilmiştir.

Kaplamanın kalınlığına göre yüzeye uygulanan kaplamalar ince film kaplamalar ve kalın film kaplamalar olarak ikiye ayrilır. İnce film kaplamalar kalınlıkları 1-10 $\mu \mathrm{m}$ arasında olan kaplamalardır ve kaplamanın birikmesi atomik düzeyde gerçekleşmektedir. Kalın film kaplamalarda ise birikme büyük kütlelerin transferi ile gerçekleşmektedir (Axen vd., 2000:13,19,26). PVD kaplamalar, sertlik, aşınma ve korozyon direncinin artırılması amacıyla yaygın olarak kullanılmasına rağmen, yüksek işlem maliyeti, sınırlı kaplama alanı, düşük kaplama hızı gibi bazı dezavantajlara da sahiptir. 
Kaplama yöntemlerinin uygulama alanının belirlenmesinde iki parametre çok büyük önem taşır. Bunlar: kaplama kalınlığı ve uygulama sıcaklığıdır (Şekil 2) (Holmberg ve Matthews, 1994:351-371).

$\mathrm{Bu}$ alanda çalışan mühendisler, ürünlerde istenen performans özelliklerini sağlayabilmenin değişik türde kaplama ile mümkün olduğunu fark etmişlerdir. Ancak; kaplama kullanıldığında bu işlem ürünün performansını artırmakla birlikte maliyetini de arttırmaktaydı. Bu ikilem onları ürünlerde performans ve üretim maliyeti dengesini sağlayabilecek yeni buhar biriktirme teknolojileri aramaya zorlamıştır (Groves vd., 2000:1-13).

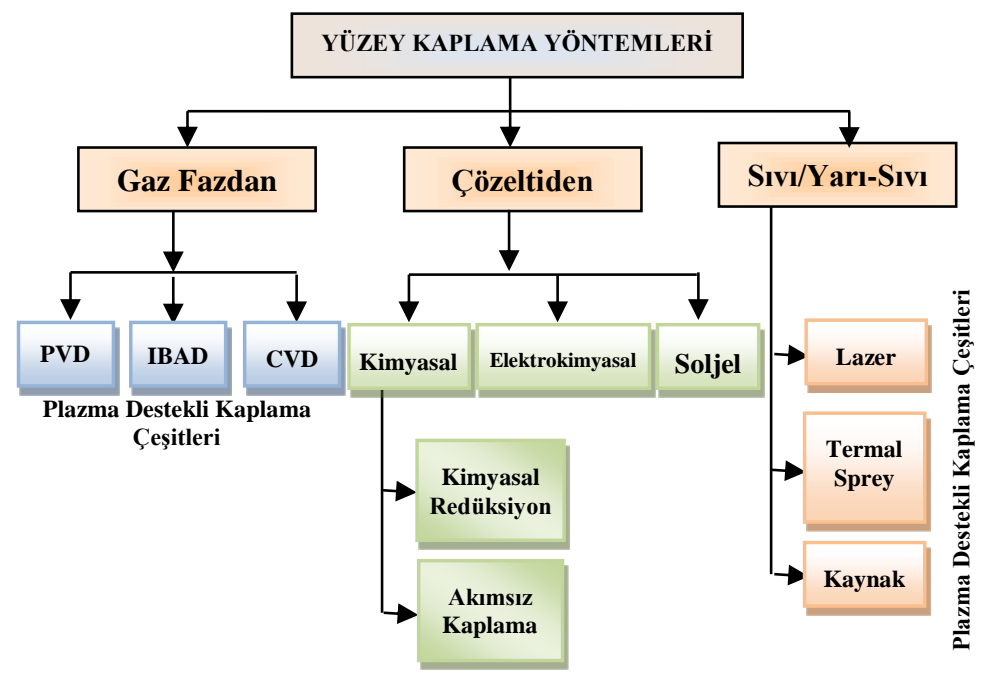

Şekil 1. Kaplanacak malzemenin bulunduğu fiziksel hale göre kaplamaların sinıflandirılması (Bunshatta, 1980:21-26). 
Fiziksel Buhar Biriktirme Yöntemlerinden PVD ve JVD/DVD İnce Film

Kaplamaların Karşılaştırılması ve DVD Kaplama Teknolojisinin Endüstriyel

Uygulamaları Üzerine Kavramsal, Akademik ve Teorik Bir Analiz

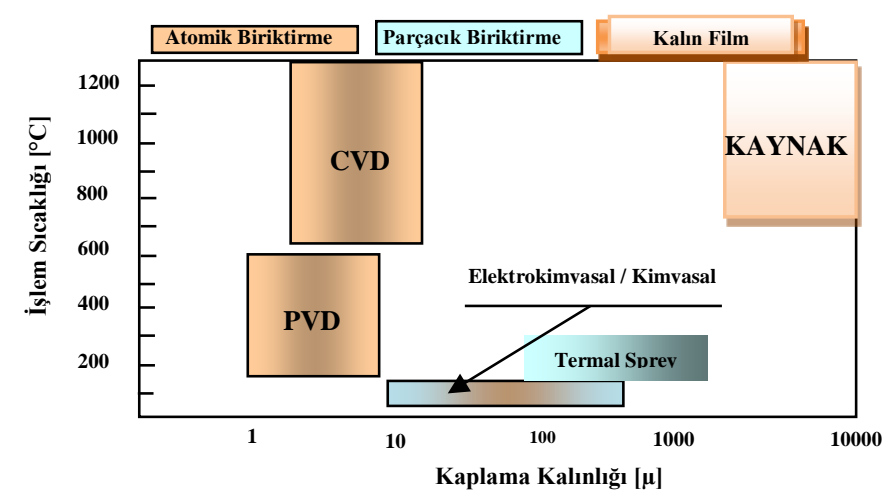

Şekil 2. Kaplanacak malzemenin bulunduğu fiziksel hale göre kaplamaların sinıflandırılmas1 (Holmberg ve Matthews, 1994:351-371).

Endüstriyel uygulamalar incelendiğinde yaygın kullanım alanlarına sahip iki tür buhar biriktirme yöntemi bulunmaktadır. Bunlar: Kimyasal Buhar Biriktirme (CVD) ve Fiziksel Buhar Biriktirme (PVD) kaplama metotlarıdır. İnce seramik film kaplamalar, gelişmiş teknolojik ürün imalatında kol saatinden kesici takımlara geniş bir yelpazede yoğun ilginin odağındaki konulardan birisidir. Bu kaplamalar, sert ve tok yapısıyla sürtünme ve aşınma özellikleri gelişmiş malzeme üretimini desteklediği gibi malzemeye dekoratif özellikler de kazandırmaktadır. Her iki kaplama yöntemi de taban malzeme üzerine $0,01-10 \mu$ arasında atomik düzeyde kaplama yapılmasına imkan vermekle birlikte, PVD yöntemi, CVD kaplamaların işlem sıcaklığına bağlı olarak (850-1250 $\left.{ }^{\circ} \mathrm{C}\right)$ taban malzemenin mikroyapısında meydana getirdiği olumsuz etkileri ortadan kaldırmıştır.

Yakın gelecekte, PVD tekniğinin çelik endüstrisine yüzey ön işlemlerinden yüzey işlemlerine değişen yelpazede yeni olanaklar sağlayacağı muhakkaktır. Bu bağlamda Metallurgical Research Centre (CRM), endüstriyel gereksinimlerle uyumlu "kuru kaplama" avantajlarına sahip olan "Jet Buharı Biriktirme (Jet Vapor 
Deposition-JVD)" olarak adlandırılan yeni bir vakum kaplama tekniği geliştirmektedir. PVD teknolojisinin, sıcak daldırma veya elektrolitik kaplama gibi geleneksel tekniklerle gerçekleştirilemeyen yeni kaplamaların üretimine de izin vereceği öngörülmektedir. JVD, bir veya daha fazla potada indüksiyonla, bir karıştırma haznesinde buhar üreterek, yakınına konumlandırılmış tek enjektörlü bir PVD sistemidir. İndüksiyonla 1sıtma sayesinde, metal için bile çok yüksek iç basınç (100 mbar'a kadar) elde edilebilir. Rezistans ile 1sıtma gibi diğer teknolojilere kıyasla direkt sıvı fazına müdahale ile daha yüksek esneklik ve daha düşük bir tepki süresi elde edilebilir. JVD, endüktif vakum teknolojisinin esnekliğini yüksek bir verimlilikle birleştirir. Bu özellikler JVD'yi endüstriyel gereksinimlerle, yani üretkenlik ve verimlilikle uyumlu hale getirir (Schmitz vd., 2000:971-978). JVD sistemi, yüksek verimlilik, yüksek dayanımlı metal, yüksek kısmi basınçta çalışma (1 mbar'a kadar), homojen metal dağılımı ve alaşım bileşimi ve iyi bir kaplama yapışması ile karakterize edilen çok kompakt bir sistemdir. (Schmitz vd., 2001:522-527).

Directed vapor deposition (DVD) kaplama teknolojisi, elektron 1şın tabanlı olarak, küçük alanlı yüzeylerin yüksek performanslı ince ve kalın filmle kaplanmasını sağlamak için geliştirilmiştir. Sonrasında 4 alandaki yeteneği birleştirilerek gelişimi sürdürülmüştür. Bu yetenekler; biriktirme hızının yüksek olmas1 $\left(5 \mu \mathrm{m} / \mathrm{min}\right.$ ve $100 \mathrm{~cm}^{2}$ den daha geniş alan), diğer kaplama teknolojilerine oranla en az 3 kat malzeme kullanım verimliliği, atomik yapının oluşturulmasında tam kontrol ve atomik yapının daha esnek tanımlanabilmesidir. Bu kriterler DVD isimli eşsiz bir plazma destekli elektron ışını ile buharlaştırma aracının gelişimini sağlamıştır (Groves vd., 2000:1-13).

Yüzey kaplama metodu olan Doğrudan Buhar Biriktirme (DVD) tekniği ile; yüksek hızlarda çalışan makine elemanlarıyla, sürtünmeye, ısıya ve aşınmaya 
Fiziksel Buhar Biriktirme Yöntemlerinden PVD ve JVD/DVD İnce Film

Kaplamaların Karşılaştırılması ve DVD Kaplama Teknolojisinin Endüstriyel

Uygulamaları Üzerine Kavramsal, Akademik ve Teorik Bir Analiz

dayanıklı, alaşım ve bileşiklerin düzlemsel ya da eğrisel yüzeylerine kaplama yapılabilmektedir (Samtaş ve Sert, 2012:30-40).

\section{PVD Kaplamalar}

Ticari amaçlı ilk PVD takım kaplama uygulaması Balzers tarafından 1979 yılında gerçekleştirilmiştir. İlk olarak bir HSS matkap ve kılavuz takımı kaplanmış olup, yöntemin uygulanışı daha sonra diğer takımlara da yaygınlaştırılmıştır. PVD kaplama uygulamaları, 1980'lerin başından beri endüstride yaygın olarak kullanılmaktadır (Kıyak vd., 2003:115-124). Endüstride, sürtünmeye maruz kalan, bu nedenle çalışmayan ve verimliliğini kaybeden sistemlerin iyileştirilmesi amaciyla PVD, CVD, DVD, Plasma ve Termal püskürtme teknikleri kullanılarak çeşitli kaplamaların yapıldığı görülmektedir. PVD yöntemi, uygulanma kolaylığı, taban malzemenin mikro yapısına zarar vermemesi, ölçüsel tolerans değişikliğine gerek duyulmaması vb. özelliklerinden dolayı yaygın olarak kullanılmaktadır (Aytaç vd., 2016:3255).

$\mathrm{Bu}$ teknik, vakum altında bulundurulan malzemelerin buharlaştırılarak veya sıçratılarak atomların yüzeyden kopartılması ve kaplama yapılacak yüzeye atomsal veya iyonsal olarak biriktirilmesi esasına dayanır.

Fiziksel buhar biriktirme işlemlerinde düşük taban malzeme sıcaklıkları ve yüksek oranda refrakter kaplama malzemeleri kullanımı sebebiyle yüksek iç gerilmeler oluşmaktadır. Ayrıca yüksek enerjili iyon bombardımanı nedeniyle iç gerilmede artış meydana gelebilmektedir. Bu işlem refrakter malzemelerin biriktirilmesinde uygun bir kaplama tekniğidir (Kusano vd., 1998:151-155).

Fiziksel Buhar Biriktirme (PVD), kısmen iyonize olmuş metal buharının üretimi, belirli gazlarla reaksiyonu ve taban malzeme üzerinde belirli bir bileşime sahip ince bir film oluşturarak metal bazlı sert kaplamaların üretilmesi için bir 
yöntemdir. En çok kullanılan yöntemler püskürtme ve katodik arktır. Püskürtme sırasında buhar, enerjik gaz iyonlarıyla bombardımana tutulan metal bir hedef tarafindan oluşturulur. Katodik ark yönteminde, malzemeyi buharlaştırmak için tekrarlayan vakum ark deşarjları kullanır. Tüm PVD işlemleri yüksek vakum koşullarında gerçekleştirilir. $\mathrm{Ti}, \mathrm{Cr}, \mathrm{Zr}$ ve $\mathrm{AlCr}$, $\mathrm{AlTi}$, TiSi gibi alaşımların nitrürler, karbürler ve karbonitridlerden oluşan kaplamalar, çok çeşitli alet ve bileşenler üzerinde ince film biriktirilmesi için kullanılır. PVD kaplamalar için tipik işlem sıcaklığı 250 ile $450^{\circ} \mathrm{C}$ arasındadır. Kaplamalar; tekli, çoklu ve kademeli tabakalar halinde de biriktirilebilir. Kaplama kalınlığ 2 ila $5 \mu \mathrm{m}$ arasında değişir, ancak birkaç yüz nanometre kadar ince veya 15 veya daha fazla $\mu \mathrm{m}$ kadar kalın olabilir (http://www.ionbond.com/technology/pvd/).

Alt tabaka malzemeleri arasında, çelikler, demir dışı metaller, tungsten karbürler ve ayrıca önceden kaplanmış plastikler bulunur. Taban malzemesinin PVD kaplaması için uygunluğu sadece birikim sıcaklığında ve elektriksel iletkenlikteki stabilitesi ile sınırlıdır. Bu alanda sert seramik film kaplamalar ile birlikte kaplama uygulamalarında son yıllarda büyük aşamalar kat edilmiştir. $\mathrm{Bu}$ malzemelerin gevrek ve çok kırılgan oluşları, dolu bir malzeme olarak kullanılmalarını engellemektedir. Bazı PVD yöntemi ile yapılan kaplama uygularına ait fiziksel özellikler Tablo 1'de gösterilmiştir (http://www.ionbond.com/technology/pvd/). 
Fiziksel Buhar Biriktirme Yöntemlerinden PVD ve JVD/DVD İnce Film

Kaplamaların Karşılaştırılması ve DVD Kaplama Teknolojisinin Endüstriyel

Uygulamaları Üzerine Kavramsal, Akademik ve Teorik Bir Analiz

Tablo 1. PVD Yöntemi ile yapilan kaplamalara ait fiziksel özellikler (http://www.ionbond.com/technology/pvd/).

\begin{tabular}{|c|c|c|c|c|c|c|}
\hline Kaplama & & $\begin{array}{c}\text { Kaplama } \\
\text { Kalınlığı } \\
(\mu \mathrm{m})\end{array}$ & $\begin{array}{c}\text { Micro Sertlik } \\
\text { (HV 0.05) }\end{array}$ & $\begin{array}{l}\text { Sürtünme } \\
\text { Katsayısı }\end{array}$ & $\begin{array}{c}\text { Çalışma, } \\
\text { Sicaklığı } \\
\left({ }^{\circ} \mathrm{C}\right)\end{array}$ & $\begin{array}{c}\text { Biriktirme } \\
\text { Sicaklığı } \\
\left({ }^{\circ} \mathrm{C}\right)\end{array}$ \\
\hline TiN & & $2-4$ & 2800 & 0.55 & 450 & 425 \\
\hline TiCN & & $2-4$ & 2800 & $0,15-0,3$ & 300 & 425 \\
\hline TiCrN & & $4-6$ & 2200 & 0.55 & 500 & 425 \\
\hline AlTiN & & $2-4$ & 3500 & 0.55 & 700 & 450 \\
\hline AlTiCrN & & $3-8$ & 3200 & 0.55 & 850 & $450-550$ \\
\hline $\mathrm{AlCrN}$ & & $2-4$ & 3000 & 0.55 & 1050 & $450-550$ \\
\hline $\mathrm{CrN}$ & & $4-6$ & 2300 & 0.55 & 700 & $150-400$ \\
\hline $\mathrm{Cr}_{2} \mathrm{~N}$ & & $2-5$ & $1500-2800$ & 0.55 & 700 & $150-400$ \\
\hline CrWN & & $5-8$ & $3000-3200$ & 0.3 & 800 & 350 \\
\hline a-C:H:W & & $4-6$ & 1600 & 0.2 & 350 & $160-250$ \\
\hline $\begin{array}{l}a-C: H: W \\
a-C: H\end{array}$ & + & $3-5$ & $2000-2800$ & 0.1 & 300 & $160-250$ \\
\hline $\mathrm{CrN}+\mathrm{a}-\mathrm{C}: \mathrm{H}$ & & $2-5$ & $2000-2800$ & 0.1 & 300 & $200-250$ \\
\hline a-C:H & & $1-3$ & $2000-2800$ & 0.1 & 300 & $160-250$ \\
\hline B4C & & $1-3$ & 3400 & 0.55 & 800 & 200 \\
\hline $\mathrm{TiCN}+\mathrm{MoS}_{2}$ & & $2-4$ & $3000+2000$ & 0.06 & 500 & $425 / 150$ \\
\hline
\end{tabular}

PVD teknikleri üç ana grup altında incelenebilir: 1) Buharlaştırma, 2) Siçratma, 3) Plazma oluşturma. Bu teknikleri birbirinden ayıran noktalar ise; buharlaştırmanın ayrı yöntemlerle yapılması veya kaplanacak parçaya vakum odasına göre negatif potansiyel uygulama (BIAS) ve plazma kullanımı gibi uygulamalardır. Farklı teknikler, kaplamanın yapısı, özellikleri ve birikme hızı gibi parametreleri yoğun olarak etkilemektedir (Bunshatta, 1980:21-26). Buharlaştırma tekniklerinden yaygın olarak kullanılan Katodik ark buharlaştırma sisteminin şematik gösterimi Şekil 3’te verilmiştir. 


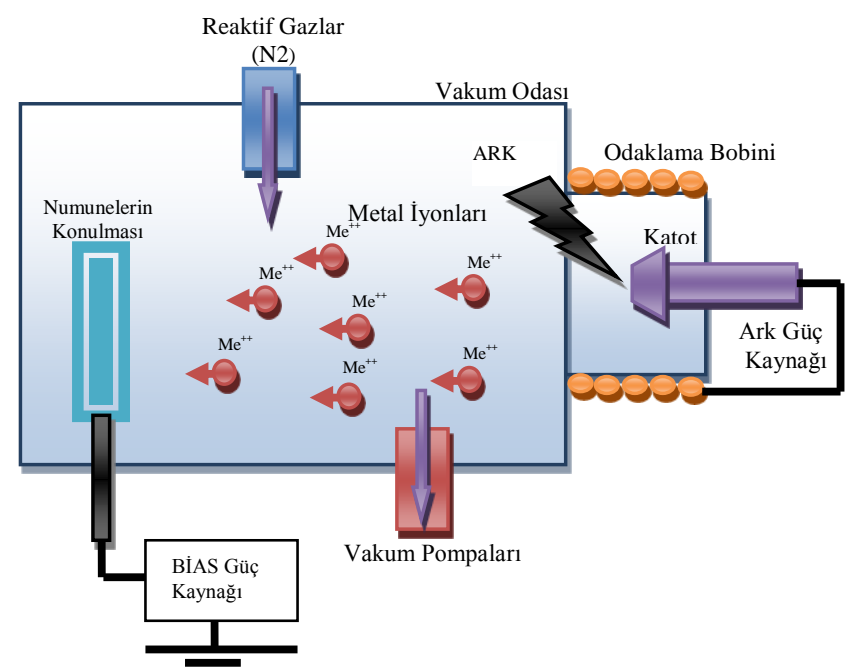

'(-)

Şekil 3. Katodik ark PVD sistemi.

$\mathrm{Bu}$ sistemde plazma içinde hareket eden iyonların kinetik enerjileri 40-100 $\mathrm{eV}$ arasındadır. Bunun sonucunda diğer tekniklere oranla daha yüksek biriktirme hızlarına ulaşılmaktadır. Damlacık sayısı azaldıkça üretilen kaplamalarda yapışma (bonding) ve aşınma özelliklerinde gelişme gözlenmektedir. Damlacıkların olumsuz etkilerinin görüldüğü uygulamalar optik ve mikro elektronik kaplamalardır. Optik kaplamalarda damlacıklar saçılma merkezleri olarak davranır ve optik kaybı artırır (Samtaş ve Sert, 2012:30-40).

\section{JVD/DVD (Jet/Doğrudan Buhar Biriktirme) Yöntemi}

Yüzey kaplama metodu olan Doğrudan Buhar Biriktirme (DVD) tekniği ile; yüksek hızlarda çalışan makine elemanlarıyla, sürtünmeye, ısıya ve aşınmaya dayanıklı, alaşım ve bileşiklerin düzlemsel ya da eğrisel yüzeylerine kaplama yapılabilmektedir. Düşük vakumda elektron ışını ile buharlaştırma yapılarak 
Fiziksel Buhar Biriktirme Yöntemlerinden PVD ve JVD/DVD İnce Film

Kaplamaların Karşılaştırılması ve DVD Kaplama Teknolojisinin Endüstriyel

Uygulamaları Üzerine Kavramsal, Akademik ve Teorik Bir Analiz

taşıyıcı gaz akımının yardımıyla metaller, seramikler ve yarı iletken malzemelerin DVD ile kaplanması gerçekleştirilebilmektedir. Buharın elde edilmesi ve kaplamanın gerçekleşmesindeki farklılıklardan dolayı DVD sistemi, Fiziksel Buhar Biriktirme (PVD) yönteminden farklı bir yapıya sahiptir. Düşük vakumda taşıyıcı gaz akımı altında çalışan DVD ile iş parçalarına buhar biriktirme esnasında akım odaklanarak verimli, bir o kadar da hızlı malzeme birikimi sağlanarak işlevsel bir nitelik kazandırılabilmektedir (Samtaş ve Sert, 2012:30-40).

DVD sistemi, taşıyıcı bir gaz akımındaki buhar atomlarını toparlar ve kaplanacak malzeme üzerinde odaklar. Bu özellik ana malzemeye ulaşan buhar atomları için birikim dağılımı ve açısının değiş̧tirilmesini mümkün hale getirmektedir. Kaplama materyalinin küçük bir alanda biriktirilmesi özelliğiyle bu alandaki uygulamalarda (kompozit malzemeler ve fiber kaplamalar) gösterdiği verimlilik yüksek düzeydedir (Samtaş ve Sert, 2012:30-40).

DVD sistemindeki vakum ortamı, diyot püskürtme sistemlerindeki basınç ortamlarına benzemektedir. DVD işlem süreci, çevresi soğutucu sistemlerle desteklenmiş bir pota içerisine yerleştirilen çubuk şeklindeki bir veya bir kaç kaplama malzemesinin elektron 1şınları ile buharlaştırılması ve taşıyıcı bir gaz yardımı ile kaplanacak malzeme üzerine elde edilen buharın doğrudan yönlendirilmesine dayanmaktadır.

DVD sistemlerin geliştirilmesi amacıyla 1990 yıllardan bu yana çok farklı çalışmalar yürütülmektedir. Virjinya Üniversitesinde, buhar biriktirme ekipmanlarındaki gelişime paralel olarak, yeni nesil DVD (DVDII) olarak adlandırılan ve $100 \mathrm{~cm}^{2}$ den daha küçük yüzeylerin daha hızlı ve etkili olarak kaplanmasını sağlayan bir sistem geliştirilmiştir. İkinci nesil DVD sistemi, üniversite araştırmaları ve FEP (Fraunhofer Enstitüsü) tarafından geliştirilen buhar biriktirme ekipmanlarının birleşiminden oluşmaktadır. $\mathrm{Bu}$ sistem beklentilere 
cevap vermesi amacıyla dört temel teknolojiyi bir araya getirmiştir: 1) Gelişmiş elektron ışın tabancası, 2) Düşük vakumda buharın kaynağından malzeme yüzeyine taşınması, 3) Kaplama yüzeyinin çevresinde plazma aktivasyonu, 4) Kaplama yüzeyine elektriksel kutuplama (Şekil 4) (Groves vd., 2000:1-13).

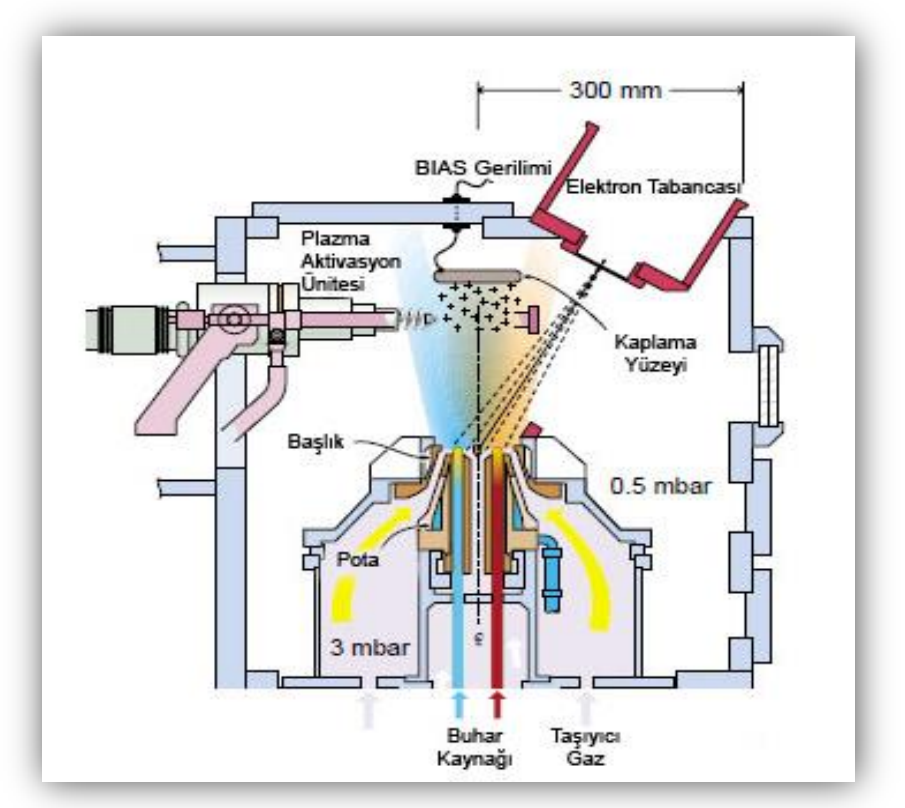

Şekil 4. İkinci nesil DVD sisteminin şematik gösterimi (Groves vd., 2000:1-13).

En temel haliyle önerilen Doğrudan Buhar Biriktirme (DVD) Sistemi Şekil 4'de görüldüğü gibi 4 esas bileşenden oluşur. PVD kaplamalarda olduğu gibi parçaların kaplanması işlemi sırası ile; buharlaştırılacak bir veya birkaç kaynak kaplama malzemesinden atom buharının oluşturulması, atom buharının işlem odasından taşıyıcı bir gaz akışı ile taşınması ve buharın taban malzeme üzerinde biriktirilmesinden oluşmaktadır. Görüldüğg̈ üzere, DVD sistemin avantajları gözönüne alındığında, gelecekte bu teknolojinin endüstriyel kaplama uygulamalarında en çok tercih edilen kaplama aracı olacağı kaçınılmazdır. 
Fiziksel Buhar Biriktirme Yöntemlerinden PVD ve JVD/DVD İnce Film

Kaplamaların Karşılaştırılması ve DVD Kaplama Teknolojisinin Endüstriyel

Uygulamaları Üzerine Kavramsal, Akademik ve Teorik Bir Analiz

Sonuç olarak, DVD ile diğer yüksek vakumlu buhar biriktirme teknikleri karşılaştırıldığında, DVD metodu diğerlerine göre, daha verimli malzeme kullanımı, daha hızlı işlem ile düz ya da eğri yüzeylerin kaplanmasında daha düşük nihai ürün maliyeti sağlamaktadır (Samtaş ve Sert, 2012:30-40).

\section{Buhar Biriktirme Yöntemli Endüstriyel Yüzey Kaplama Uygulamalarında Karşılaştırma}

Günümüzde ülkelerin etkili ve güçlü silahlara sahip olması savunma sanayindeki teknolojik gelişmeler ile ilişkilendirilmektedir. Bir ülkenin ulusal teknolojisi, öncelikle savunma sanayindeki gelişmişlikle ölçülmektedir. Endüstride, sürtünmeye maruz kalan, bu nedenle çalışmayan ve verimliliğini kaybeden sistemlerin iyileştirilmesi amaciyla PVD, CVD, DVD, Plasma ve Termal püskürtme teknikleri kullanılarak çeşitli kaplamaların yapıldığı görülmektedir. Ancak, ülkemizde teknolojik gelişmelerin öncülügünü yapan savunma sektöründe PVD vb. ince seramik film kaplamaların kullanılması, gerek farkındalık eksikliğinden, gerekse ürün maliyetlerine getirdiği yükler açısından yeterince yaygın değildir (Aytaç vd., 2016:3255).

Sıçratma, buharlaştırma ve plazma oluşturma tekniklerinin ortaya çıkışı, düşük büyüme oranlarında $(<1 \mu \mathrm{m} / \mathrm{dak})$ ince filmlerin atomik birleşimine izin verir (Hubler, 1994:327). 

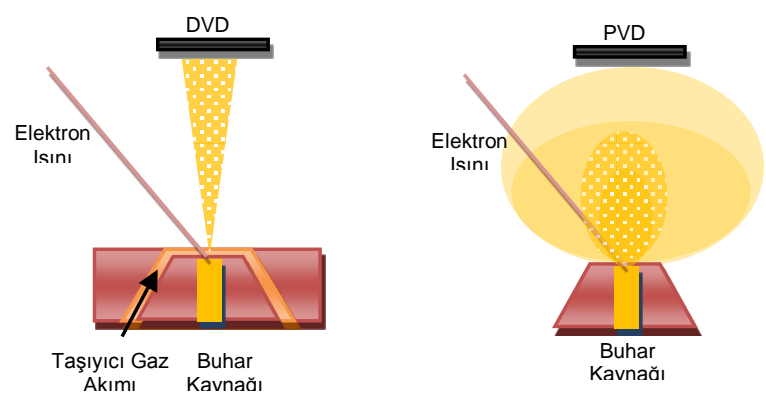

Şekil 5. DVD ve PVD sistemin temel farklılıkları (Groves vd., 2000:1-13).

PVD sisteminin aksine, DVD sistemlerde buhar atomlarının taşınması son derece hassas ve kontrollü bir şekilde gerçekleştirilmektedir. PVD sistemlerinde biriktirilen buharın bir kısmı vakum odası duvarlarına yönelmekte ve malzeme kaybına neden olabilmektedir. Ayrıca işlem zamanı uzun olmakta ve karmaşık parçaların kaplanmasında sorunlar yaşanmaktadır. DVD sisteminde basit bir mekanik pompanın çok kısa sürede elde ettiği vakum ortamında buharlaşan metal atomlarının taşıyıcı gaz ile yönlendirilmesi sonucunda tüm bu olumsuz etkiler ortadan kaldırılmaktadır. PVD ve DVD sisteminin temel farklılığını ortaya koyan şematik gösterim Şekil 5'te gösterilmiştir (Groves vd., 2000:1-13).

DVD kaplama uygulamalar, DVD ve yeni nesil kaplama teknolojileri geliştirmek amaciyla kurulan DVTI (Directed Vapor Technologies International, Inc.) firması tarafından havacılık ve uzay sanayinde başarıyla uygulanabilmektedir. Bu firma Virjinya Üniversitesi ile DVD kaplamaların geliştirilmesi konusunda ortak çalışmalar da yürütmektedir. Firma DVD kaplama teknolojilerini; havacılık alanında, gaz türbin motorlarında, enerji depolama cihazlarında, tıp ve optik cihazlarında başarıyla uygulamaktadır. DVD kaplamaların geliştirilmesi ve endüstriyel uygulamaları konusunda çalışmalar halen devam etmektedir. $\mathrm{Bu}$ 
Fiziksel Buhar Biriktirme Yöntemlerinden PVD ve JVD/DVD İnce Film

Kaplamaların Karşılaştırılması ve DVD Kaplama Teknolojisinin Endüstriyel

Uygulamaları Üzerine Kavramsal, Akademik ve Teorik Bir Analiz

konuda çalışan az sayıda firma bulunmakla birlikte DVD kaplama teknolojileri konusunda gelinen nokta umut verici düzeydedir.

Yönlendirilmiş Buhar Biriktirme (DVD) prosesi, iyi biriken metal malzemelerin, polimer elyaflar, karbon fiberler ve karbon nanotüp fiberler üzerine yüksek hızlarda biriktirilmesinde etkilidir. Daha hafif ağırlıklı iletkenler ve daha hafif ağılıktaki kablolar, uzay aracı için fırlatmada ve/veya uçaklar için yakıt tüketiminde önemli ölçüde tasarruf sağlar (http://directedvapor.com/applications2/).

Son zamanlarda DVTI tarafından DVD III olarak adlandırılan yeni nesil, tamamen operasyonel üretim yeteneğine sahip DVD sistemi geliştirilmiştir. $\mathrm{Bu}$ sistemde yer alan özel olarak tasarlanmış kaplama odası; küçük değişikliklerle birlikte özel parçaların kaplanması ve üretim hattında esnekliği sağlamaktadır. DVD III sistemi, $60 \mathrm{~kW}$ elektron 1 şı tabancası ile çoklu kaynaklardan buharlaştırma yapabilmektedir. 75 kV'lık yüksek çalışma gerilimi, biriktirme alanını artırmakta, pompa çalışma zamanını azaltmaktadır. Tamamen bilgisayar kontrollü yürütülen kaplama işlemi tekrarlanabilir biriktirme sağlamakta ve çalışma başına maliyeti azaltmaktadır (Groves vd., 2000:1-13).

İşlevsel olarak derecelendirilmiş birçok malzeme tasarımlarının gerçekleştirilmesi için ihtiyaç duyulan hacimsel olarak homojen mikroyapıların, günümüz malzeme sentezi / işleme teknolojileri ile yapılması zordur. PVD ile tam olarak karşılanamayan bu ihtiyaçlar için, yeni bir yönlendirilmiş buhar biriktirme (DVD) tekniği geliştirilmiştir. Biriktirmeyi kontrol eden en önemli işlem parametrelerinden ikisi, taşıyıcı gaz hızı ve biriktirme odası basıncıdır. Belirli koşullar altında, DVD yönteminin, geleneksel yüksek vakumlu PVD gibi buhar biriktirme tekniklerinden çok daha yüksek bir verime sahip olduğu gözlemlenmiştir. (Groves ve Wadley, 1997:57). PVD ve DVD kaplama yöntemleri 
ile alaşım elementi biriktirmede, DVD yöntemi ile altlık üzerine daha verimli ve yüksek homojenlikte alaşım elemti oluşturabildiğini gösteren şematik gösterim Şekil 6 ve Şekil 7'de verilmiştir (Hass, Groves ve Wadley, 2001:81-87). Buhar biriktirme oranları birçok faktöre (gaz akış hızı, nozzle çapı, oda basıncı, taban malzeme sıcaklığı vb.) bağlı olmasına rağmen literatür çalışmalarından elde edilen ortalama kaplama biriktirme oranları Tablo 2'de verilmiştir (Hass, Groves ve Wadley, 2001:81-87, Yu, Hass ve Wadley, 2005:43-52, Samtaş ve Sert, 2012:3040).

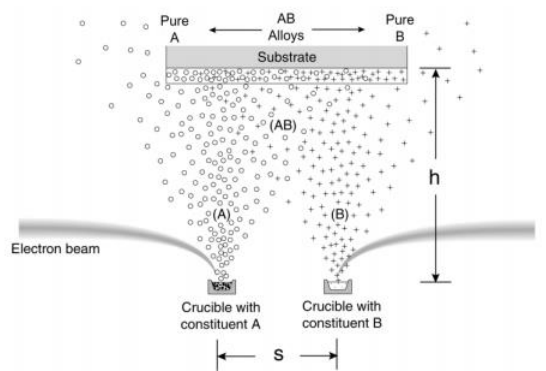

Şekil 6. Geleneksel PVD elektron 1şını buharlaşmasını kullanarak alaşım biriktirmeyi gösteren şematik çizim.

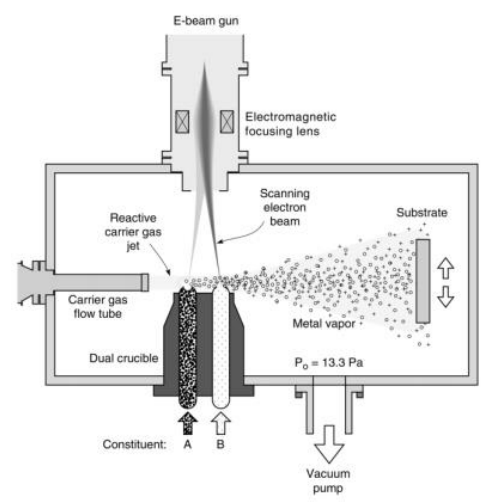

Şekil 7. DVD elektron 1şını buharlaşmasını kullanarak alaşım biriktirmeyi gösteren şematik çizim.

Tablo 2. PVD ve JVD/DVD Kaplama Yöntemlerinin ortalama buhar biriktirme aralıkları.

\begin{tabular}{l|l} 
Kaplama Tekniği & Biriktirme Oranı \\
\hline PVD & $0,2-0,8 \mu \mathrm{m} /$ Dakika \\
\hline DVD/JVD & $0,5-10 \mu \mathrm{m} /$ Dakika
\end{tabular}


Fiziksel Buhar Biriktirme Yöntemlerinden PVD ve JVD/DVD İnce Film Kaplamaların Karşılaştırılması ve DVD Kaplama Teknolojisinin Endüstriyel Uygulamaları Üzerine Kavramsal, Akademik ve Teorik Bir Analiz

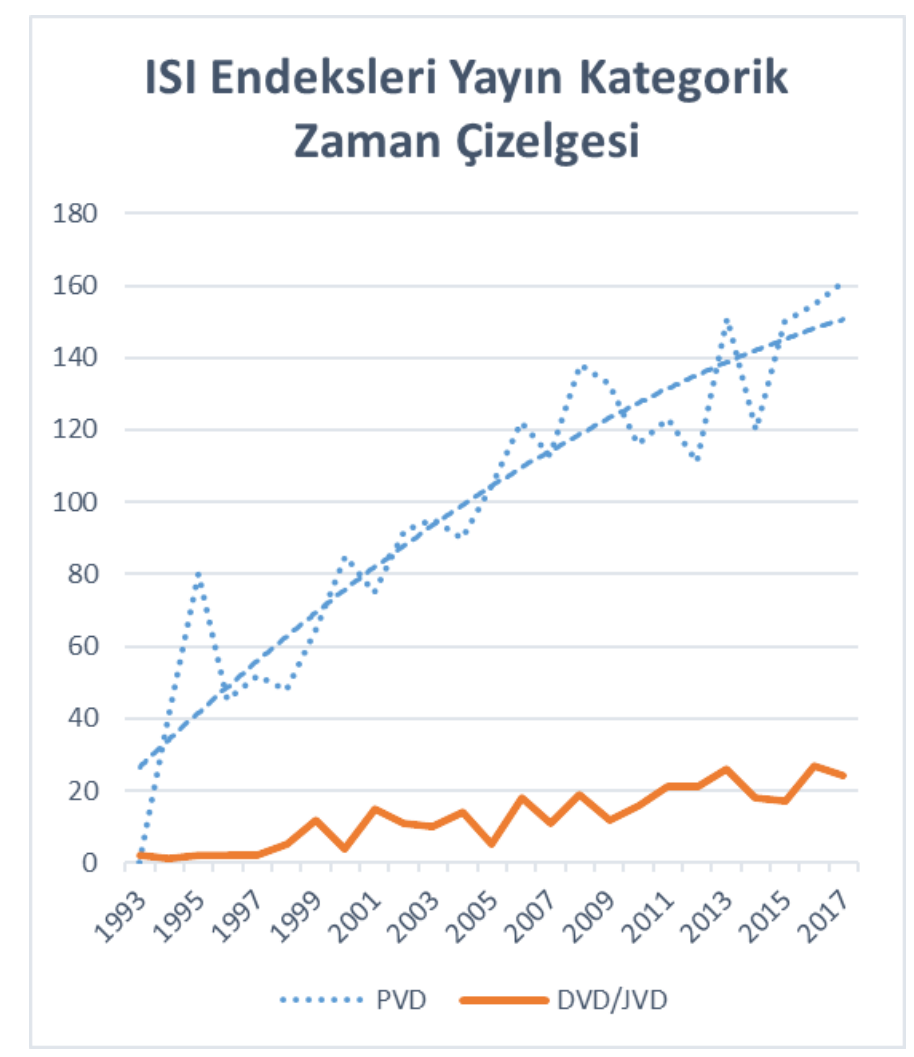

Grafik 1. ISI Endekslerinde yer alan yayınların kategorik zaman grafiği.

Literatür taramasından yıllara göre (1993-2017 arası) çalışılan konular kategorize edilerek zamana bağlı olarak ISI endekslerinde yer alan yayın sayıları analiz edilmiştir (Grafik 1). Ayrıca ülkemizde konu ile ilgili ULAKBİM'de taranan dergilerde de aynı kategoride yayımlanmış makaleler incelenmiş ve elde edilen sayılar uluslararası yayın sayıları ile kıyaslanmıştır (Grafik 2). 1980'li yıllarda geliştirilen PVD kaplamalara ilişkin akademik yayınlarda zamana bağlı olarak ilginin arttığı, 1995'li yıllarda PVD sisteminin geliştirilmesi sonrasında, yeni nesil JVD/DVD cihazların kullanımının hala yaygın olmaması nedeniyle bu alandaki 
çalışmalara ilginin zamanla arttığı ancak halen sınırlı sayıda kaldığı görülmektedir (Grafik 1). Ülkemizde ince film kaplamalar konusunda yapılan çalışmalar yetersiz kalmaktadır. Sinırlı sayıda PVD kaplama yapan firma bulunması ve kaplama ünitelerinin çok pahalı sistemler olması nedeniyle akademisyenlerin bilimsel çalışmalarında bu alanlara eğilmesi de sınırlı olmaktadır.

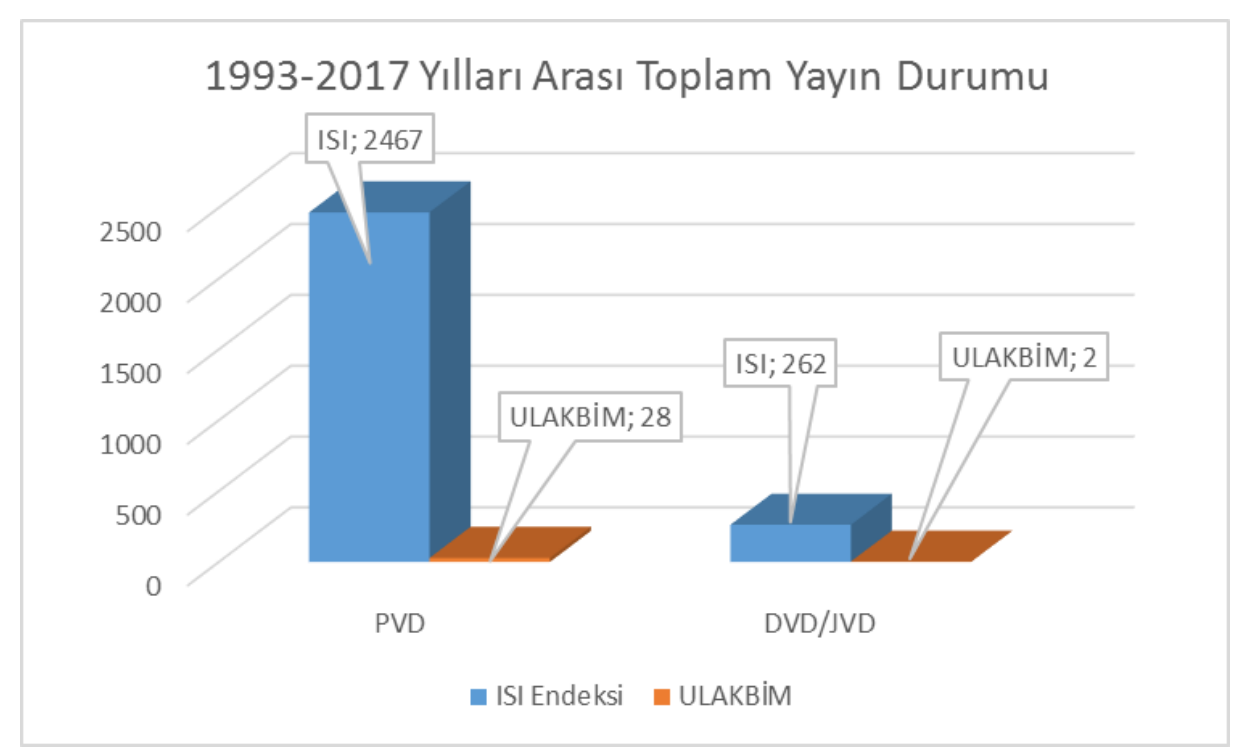

Grafik 2. ISI Endeksleri-ULKBİM'de yer alan yayın sayılarının kategorik olarak karşılaştırılması.

\section{Sonuç ve Değerlendirme}

PVD sisteminin sahip olduğu dezavantajlar DVD sistemlerin doğuşuna ve gelişimine yol açmıştır. DVD sisteminde süpersonik bir gaz akışı kullanılması, farklı buhar kaynaklarının karışmasını da sağlayarak diğer yöntemlerle elde edilmesi zor olan bileşik ve alaşımlarla hızlı bir kaplama oluşturulmasını sağlamaktadır (Samtaş ve Sert, 2012:30-40). 
Fiziksel Buhar Biriktirme Yöntemlerinden PVD ve JVD/DVD İnce Film

Kaplamaların Karşılaştırılması ve DVD Kaplama Teknolojisinin Endüstriyel

Uygulamaları Üzerine Kavramsal, Akademik ve Teorik Bir Analiz

DVD metodu ile karmaşık yapıdaki farklı yüzeylere aynı anda değişik türde kaplama yapılabilmektedir. Tamamıla bilgisayar kontrollü olarak gerçekleştirilen bu sistemde zaman kaybı olmaksızın değişik kaplamalar uygulanabilmektedir. DVD sistemlerinde işlem hızının artırıldığı ve işlem maliyetinin önemli ölçüde düşürüldüğü görülmektedir. DVD sistemlerinin diğer geleneksel kaplama yöntemlerine göre belli başlı avantajlarını şu şekilde sıralamak mümkündür;

- Yüksek oranda verimli birikim: Buhar ve gaz jeti arasındaki etkileşim istenilen bölgeye ( $\left.>10 \mu \mathrm{m} \mathrm{min}^{-1}\right)$ etkili bir şekilde yönlendirilebilmektedir.

- Karmaşık yüzeylerde birikim: Gaz jeti, buhar halindeki atomlarının kaplanacak malzemenin iç bölgelerine ulaştırılmasına yardım eder, böylece karmaşı yüzeylere sahip parçaların kaplanması mümkün hale gelmektedir.

- Birden fazla buhar kaynağının kontrollü karışımı: Yüksek frekans kullanılarak yapılan elektron 1şın taraması (100 kHz), çoklu kaynaktan aynı anda buharlaşmayı sağlamaktadır. Gaz jeti ile buharlaşan atomların etkileşimleri yeni bileşiklerin kontrollü bir şekilde oluşturulmasına imkan vermektedir.

- Düşük işlem maliyeti: Verimli bir şekilde biriktirilen ve yönlendirilen buharın, etkin ve hızlı bir şekilde kontrollü olarak kullanılması işlem maliyetlerini önemli ölçüde düşürmektedir (Groves vd., 2000:1-13).

Sonuç olarak, geleneksel kaplama sistemlerinin aksine DVD III sistemi ile karmaşık yüzeyler üzerinde dahi çok hızlı ve düşük maliyetli farklı kaplamaların yapılması mümkün hale gelmiştir. PVD kaplama sistemlerinin dezavantajlarını tamamen ortadan kaldıran üçüncü nesil DVD kaplama teknolojilerinin endüstriyel uygulamalarda kullanılması kaçınılmazdır. Ancak, ülkemizde bu konuda yatırım bulunmadığı gibi DVD teknolojileri konusunda da yeterli bilgi birikiminden söz etmek mümkün değildir. DVD sistemlerin avantajları gözönüne alındığında, 
özellikle yüksek teknoloji ürünlerinin kullanıldığı havacılık ve uzay sanayinde kullanılması kaçınılmazdır. Ülkemizin yüksek teknoloji gerektiren ürünlerin imal edilmesinde katettiği mesafe dikkate değer bir seviyededir. Kaplama teknolojilerinin üstün özellikli malzemelere ulaşmada en etkili yol olduğu düşünüldüğünde, PVD sistemlere ilave olarak mutlaka DVD sistemlere gerekli yatırımların yapılması gerekmektedir. Böylece bu alandaki gelişime önemli bir katk1 sağlanabileceği değerlendirilmektedir.

\section{Extended Summary}

\section{Introduction}

The purpose of surface engineering; to provide suitable technologies that will provide the most economical and optimum surface property designs for specific industrial applications. Thin ceramic film coatings produced using Physical Vapor Deposition (PVD) methods are an effective method of increasing the wear resistance of the material, as well as significantly affecting the service life and commercial value of the substrate when appropriate coating parameters are selected (Huang etc., 2003:7-14).

In particular, under the leadership of the aerospace sector, in parallel with the development of technology in the design of new materials has become searchable superior mechanical properties. Similar to the increase in the use of coating materials in the construction sector, the desired product characteristics in the machine and manufacturing industries can only be achieved economically by coating. The coating methods can be basically examined under three main headings according to the physical state of the coating material; coatings made from gas, solution, liquid or semi-liquid. These headings and the subheadings that can be grouped according to their specific characteristics are shown in Fig 1. 
Fiziksel Buhar Biriktirme Yöntemlerinden PVD ve JVD/DVD İnce Film Kaplamaların Karşılaştırılması ve DVD Kaplama Teknolojisinin Endüstriyel Uygulamaları Üzerine Kavramsal, Akademik ve Teorik Bir Analiz

Engineers working in this area have realized that it is possible with different types of coatings to achieve the desired performance characteristics of the products. However, when the coating was used, this process increased the performance of the product and increased the cost. This dilemma forced them to search for new vapor deposition technologies that could provide performance and cost savings in products (Groves etc., 2000:1-13).

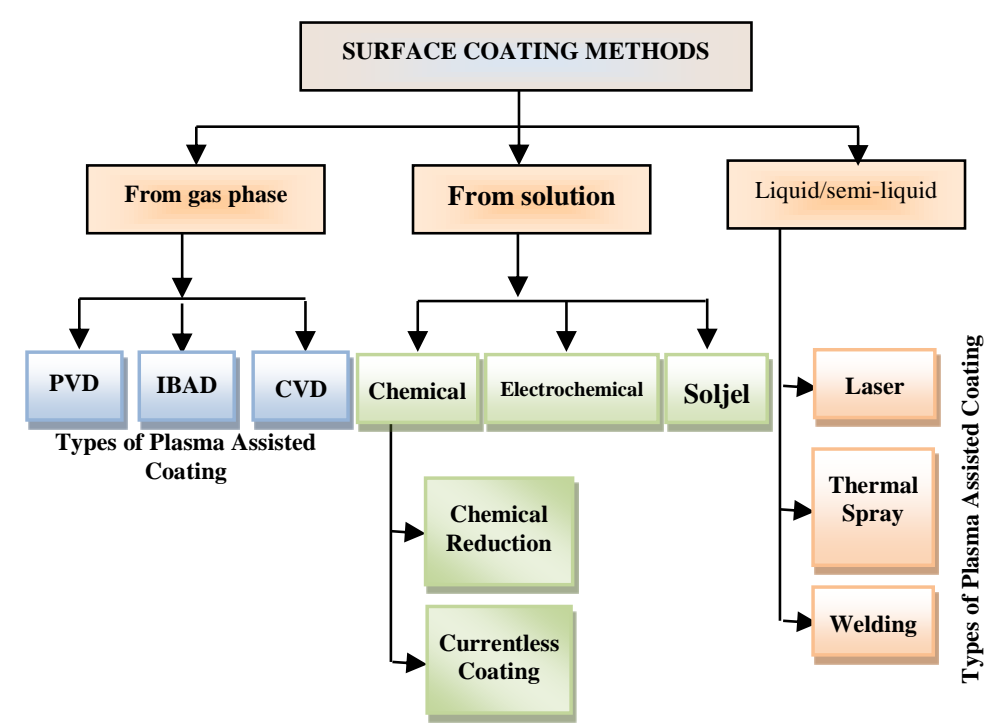

Figure 1. Classification of coatings according to physical properties of the material to be coated (Bunshatta, 1980:21-26). 


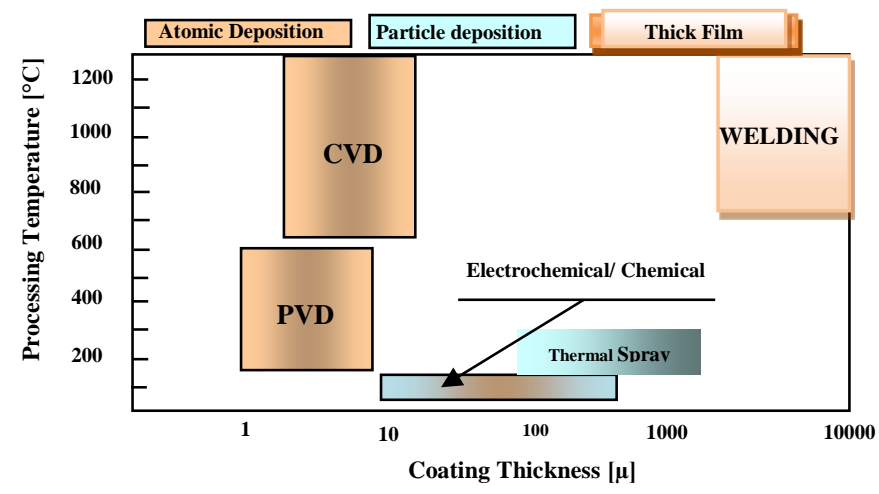

Figure 2. Classification of coatings according to the physical state of the material to be coated (Holmberg and Matthews, 1994:351-371).

When industrial applications are examined, there are two types of vapor deposition methods with common areas of use. These are Chemical Vapor Deposition (CVD) and Physical Vapor Deposition (PVD) coating methods. Both coating methods allowed the coating to be applied at a level of $0.01-10 \mu \mathrm{m}$ on the base material, but the PVD method removed the negative effects on the microstructure of the substrate material $\left(850-1250{ }^{\circ} \mathrm{C}\right)$ depending on the process temperature of the CVD coatings.

Directed vapor deposition (DVD) coating technology has been developed for electron beam-based coating of small-area surfaces with high-performance thin and thick film. After that, the ability of four areas was combined and continued to develop. These skills are; $\left(5 \mu \mathrm{m} / \mathrm{min}\right.$ and $100 \mathrm{~cm}^{2}$ wider area), at least 3 times material utilization efficiency compared to other coating technologies, full control of atomic structure formation and more flexible identification of atomic structure. These criteria provided the development of a vaporization vehicle with a unique plasma-assisted electron beam called DVD. (Groves etc., 2000:1-13). 
Fiziksel Buhar Biriktirme Yöntemlerinden PVD ve JVD/DVD İnce Film

Kaplamaların Karşılaştırılması ve DVD Kaplama Teknolojisinin Endüstriyel

Uygulamaları Üzerine Kavramsal, Akademik ve Teorik Bir Analiz

\section{PVD Coatigs}

In industry; PVD, CVD, DVD and Plasma-Thermal spray techniques have been used to make various coatings. The aim here is to improve the systems which are exposed to friction and which do not work for this reason or which lose their productivity. The PVD method is widely used because of its ease of application, not damaging the microstructure of the base material, not affecting the dimensional tolerance, and so on (Aytaç etc., 2016:3255).

This technique is based on the principle that atoms are separated from the surface by evaporation or sputtering of the material stored under vacuum and deposited atomically or ionically on the surface to be coated.

Physical Vapor Deposition (PVD) is a method for producing metal-based hard coatings by means of generation of partially ionized metal vapor, its reaction with certain gases and by forming a thin film with a specified composition on the substrate. Most commonly used methods are sputtering and cathodic arc. In sputtering, the vapor is formed by a metal target being bombarded with energetic gas ions. Cathodic arc method uses repetitive vacuum arc discharges to strike the metal target and to evaporate the material. All PVD processes are carried out under high vacuum conditions. PVD process is used for the deposition of coatings made of nitrides, carbides and carbonitrides of $\mathrm{Ti}, \mathrm{Cr}, \mathrm{Zr}$ and alloys like AlCr, AlTi, TiSi on a large range of tools and components. Applications include cutting and forming tools, mechanical components, medical devices and products that benefit from the hard and decorative features of the coatings. The typical process temperature for PVD coatings is between 250 and $450{ }^{\circ} \mathrm{C}$. In some cases, Ionbond PVD coatings can be deposited at temperatures below $70{ }^{\circ} \mathrm{C}$ or up to $600{ }^{\circ} \mathrm{C}$, depending on substrate materials and expected behavior in the application. The coatings can be deposited as mono-, multi- and graded layers. The latest generation films are nano- 
structured and superlattice variations of multi-layered coatings, which provide enhanced properties. The coating structure can be tuned to producing the desired properties in terms of hardness, adhesion, friction etc. The final coating choice is determined by the demands of the application. The coating thickness ranges from 2 to $5 \mu \mathrm{m}$, but can be as thin as a few hundred nanometers or as thick as 15 or more $\mu \mathrm{m}$ (http://www.ionbond.com/technology/pvd/).

\section{JVD/DVD (Jet/ Directed Vapor Deposition) Method}

With Direct Vapor Deposition (DVD), a surface coating method; can be coated plane or curvilinear surfaces of friction, heat and abrasion-resistant alloys, compounds and machine elements operating at high speeds. By evaporation with electron beam in low vacuum, metals, ceramics and semi-conductor materials can be coated with DVD with the help of carrier gas flow. Because of the differences in vapor acquisition and coating realizations, the DVD system has a different structure than the Physical Vapor Deposition (PVD) method. The DVD, which runs under carrier gas flow at low vacuum, focuses the flow during vapor deposition on the workpieces, providing a productive, fast material deposition and a functional qualification (Samtaş and Sert, 2012:30-40).

The DVD system collects vapor atoms in a carrier gas stream and focuses on the material to be coated. This feature makes it possible to distribute the deposition and change the angle of the vapor atoms reaching the main material. With the ability to deposit the coating material in a small area, the efficiency of the application (composite materials and fiber coatings) in this area is high (Samtaş and Sert, 2012:30-40).

The vacuum environment in the DVD system is similar to the pressure atmosphere in the diode spray system. The DVD processing process is based on the evaporation of one or several bar-shaped coating materials placed in a pot 
Fiziksel Buhar Biriktirme Yöntemlerinden PVD ve JVD/DVD İnce Film

Kaplamaların Karşılaştırılması ve DVD Kaplama Teknolojisinin Endüstriyel

Uygulamaları Üzerine Kavramsal, Akademik ve Teorik Bir Analiz

supported by surrounding cooling systems with electron beams and directing the vapor obtained on the material to be coated with the aid of a carrier gas.

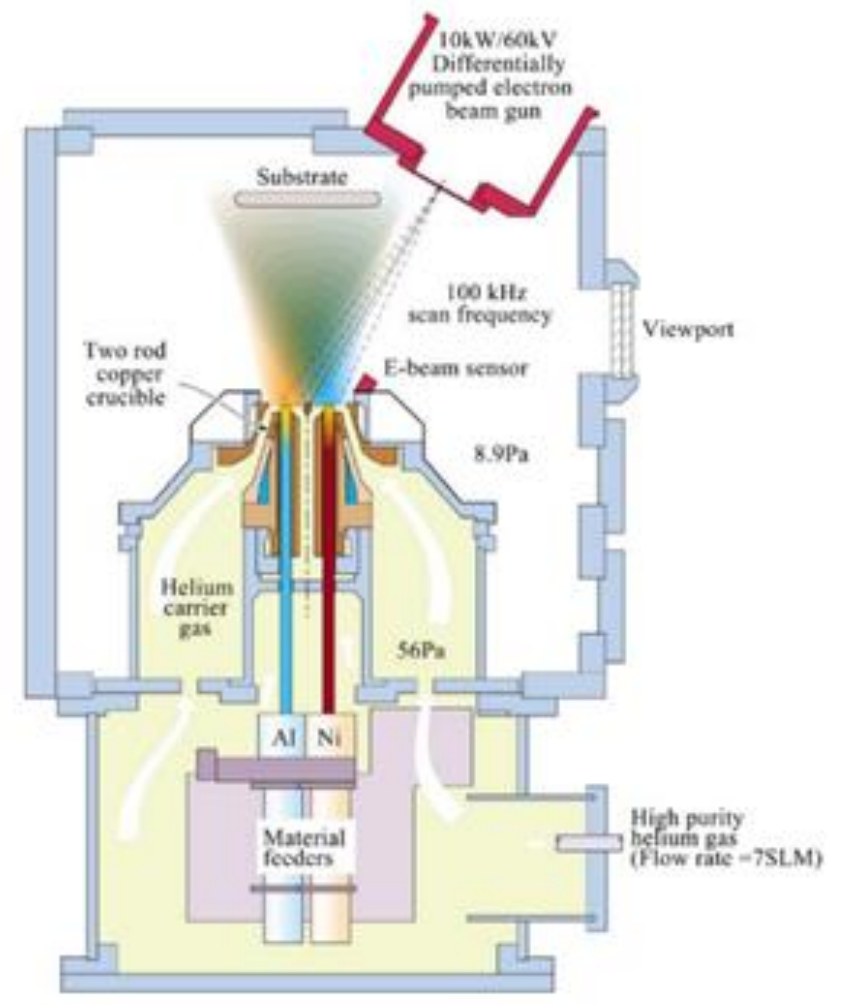

Figure 4. Schematic presentation of the DVD system (Yu, Hass and Wadley, 2005:43-52).

The Direct Vapor Deposition (DVD) System, which is proposed in its most basic form, consists of 4 basic components as shown in Figure 4. Coating of the parts as in PVD coatings is done in sequence; the formation of atomic vapor from one or more source coating materials to be vaporized is carried out by transporting the atomic vapor from the process chamber by a carrier gas stream and depositing the vapor on the substrate. As can be seen, given the advantages of the DVD 
system, it is inevitable that this technology will become the most preferred coating tool in industrial coating applications in the future.

As a result, when compared to DVD and other high vacuum vapor deposition techniques, the DVD method provides the use of more efficient material, faster processing and lower final product cost when coating flat or curved surfaces, compared to others (Samtaş and Sert, 2012:30-40).

\section{Comparison of Industrial Surface Coating Applications By Vapor Deposition Method}

Today, the fact that countries have effective and powerful weapons is associated with technological developments in the defense industry. The national technology of a country is measured primarily by the development of the defense industry. It has been observed that various coatings have been made using PVD, CVD, DVD, Plasma and Thermal spraying techniques in order to improve frictionfree, non-working and productivity-losing systems in industry. However, in the defense sector, which is the pioneer of technological developments in our country, PVD and so on. the use of thin ceramic film coatings is not widespread enough in terms of the lack of awareness, and the burdens that are required for product costs (Aytaç etc., 2016:3255).

Sputtering, evaporation and plasma generation techniques allows atomic assembly of thin films at low growth rates $(<1 \mu \mathrm{m} / \mathrm{min})$ (Hubler, 1994:327). 
Fiziksel Buhar Biriktirme Yöntemlerinden PVD ve JVD/DVD İnce Film

Kaplamaların Karşılaştırılması ve DVD Kaplama Teknolojisinin Endüstriyel

Uygulamaları Üzerine Kavramsal, Akademik ve Teorik Bir Analiz
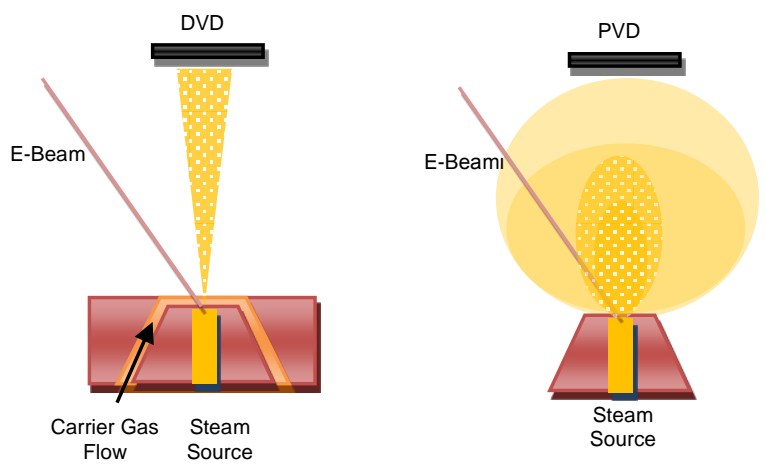

Figure 5. Main differences of DVD and PVD system (Groves etc., 2000:1-13).

Unlike PVD systems, the transport of vapor atoms in DVD systems is very precise and controlled. Some of the vapor deposited in PVD systems is directed to the vacuum chamber walls and can cause material loss. In addition, the processing time is long and there are problems in coating complex parts. As a result of directing the metal atoms evaporated in the vacuum system of the DVD system, which is obtained by a simple mechanical pump in a very short time, with carrier gas, all these negative effects are eliminated. A schematic representation showing the fundamental difference of the PVD and DVD system is shown in Figure 5 (Groves etc., 2000:1-13).

DVD coating applications can be successfully applied by aviation and aerospace industries by DVTI (Directed Vapor Technologies International, Inc.), which is established to develop DVD and next generation coating technologies. This company is also cooperating with the University of Virginia on the development of DVD coatings. This company offers DVD coating technologies; in aviation, gas turbine engines, energy storage devices, medical and optical devices. Work on the development of DVD coatings and industrial applications is still 
ongoing. With few companies working in this area, the point reached for DVD coating technologies is promising.

The Directed Steam Deposition (DVD) process is effective when highspeed deposition of well-deposited metal materials, polymer fibers, carbon fibers, and carbon nanotube fibers occurs. Lighter weight conductors and lighter weight cables provide significant savings in fuel consumption for launching for spacecraft and / or for aircraft (http://directedvapor.com/applications-2/).

A schematic representation is shown in Figs. 6 and 7, showing that PVD and DVD coating methods and alloying element deposition can produce a more efficient and highly homogeneous alloy element on the substrate with the DVD method (Hass, Groves and Wadley, 2001:81-87). Although the vapor deposition rates depend on many factors (gas flow rate, nozzle diameter, room pressure, substrate temperature, etc.), the average coating deposition rates obtained from literature studies are given in Table 2 (Hass, Groves and Wadley, 2001:81-87, Yu, Hass and Wadley, 2005:43-52, Samtaş and Sert, 2012:30-40).

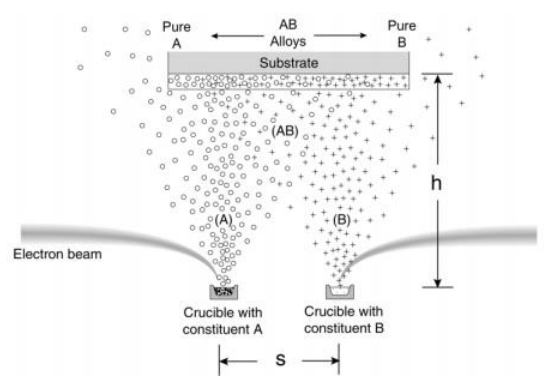

Figure 6. Schematic drawing showing alloy deposition using conventional PVD electron beam evaporation.

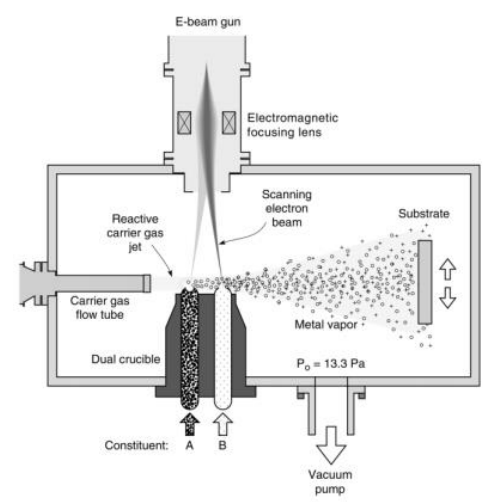

Figure 7. Schematic drawing showing alloy deposition using DVD electron beam evaporation. 
Fiziksel Buhar Biriktirme Yöntemlerinden PVD ve JVD/DVD İnce Film Kaplamaların Karşılaştırılması ve DVD Kaplama Teknolojisinin Endüstriyel Uygulamaları Üzerine Kavramsal, Akademik ve Teorik Bir Analiz

Table 2. Average vapor deposition intervals of PVD and JVD / DVD Coating Methods.

\begin{tabular}{|l|l|}
\hline Coating Technique & Deposition Rate \\
\hline PVD & $0,2-0,8 \mu \mathrm{m} / \mathrm{min}$ \\
\hline DVD/JVD & $0,5-10 \mu \mathrm{m} / \mathrm{min}$ \\
\hline
\end{tabular}

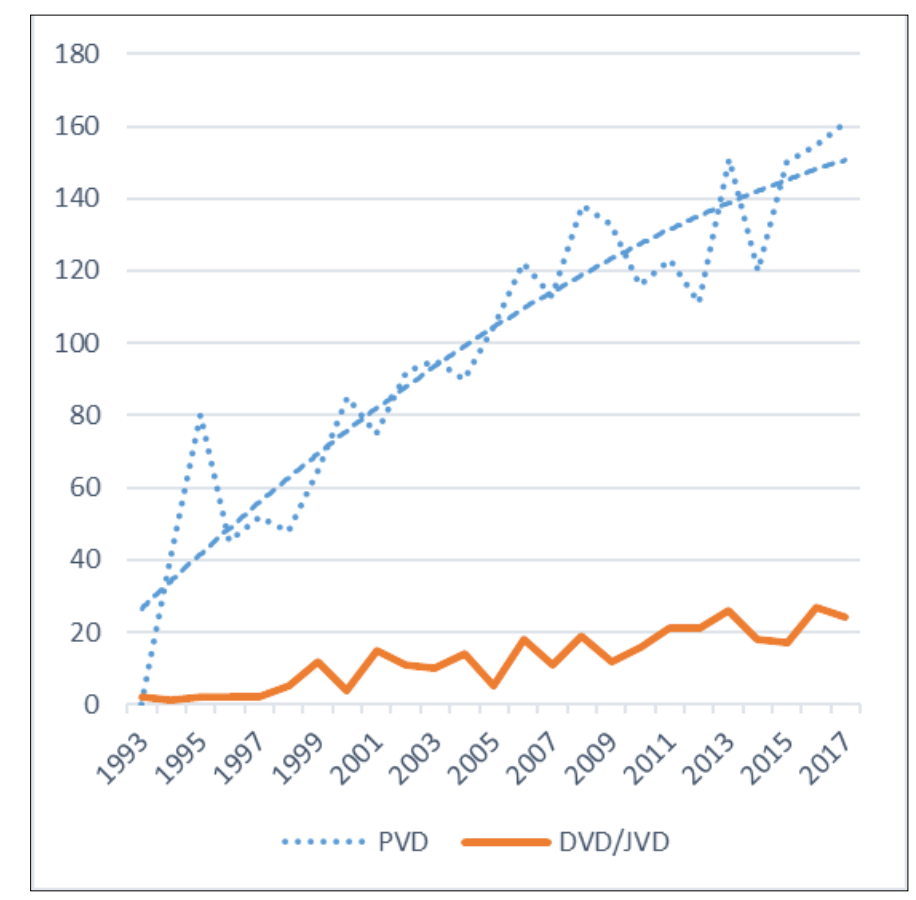

Graph 1. Categorical time graph of the publications in the ISI Index.

According to the years of literature review (between 1993 and 2017), the topics studied were categorized and the number of publications in the ISI indexes were analyzed according to the time (Graph 1). In addition, published articles in the same category were also examined in the journals scanned in ULAKBIM in our 
country and the numbers obtained were compared with the international publications (Graph 2). Since the use of next generation JVD / DVD devices is still not widespread after the development of the PVD system in 1995, due to the timedependent increase in the academic publications on PVD coatings developed in the 1980s, the interest in this area has increased over time but remains limited. Studies on thin film coatings in our country are inadequate. Due to the limited number of PVD coating companies and coating units being very expensive systems, academicians have limited exposure to these areas in their scientific work.

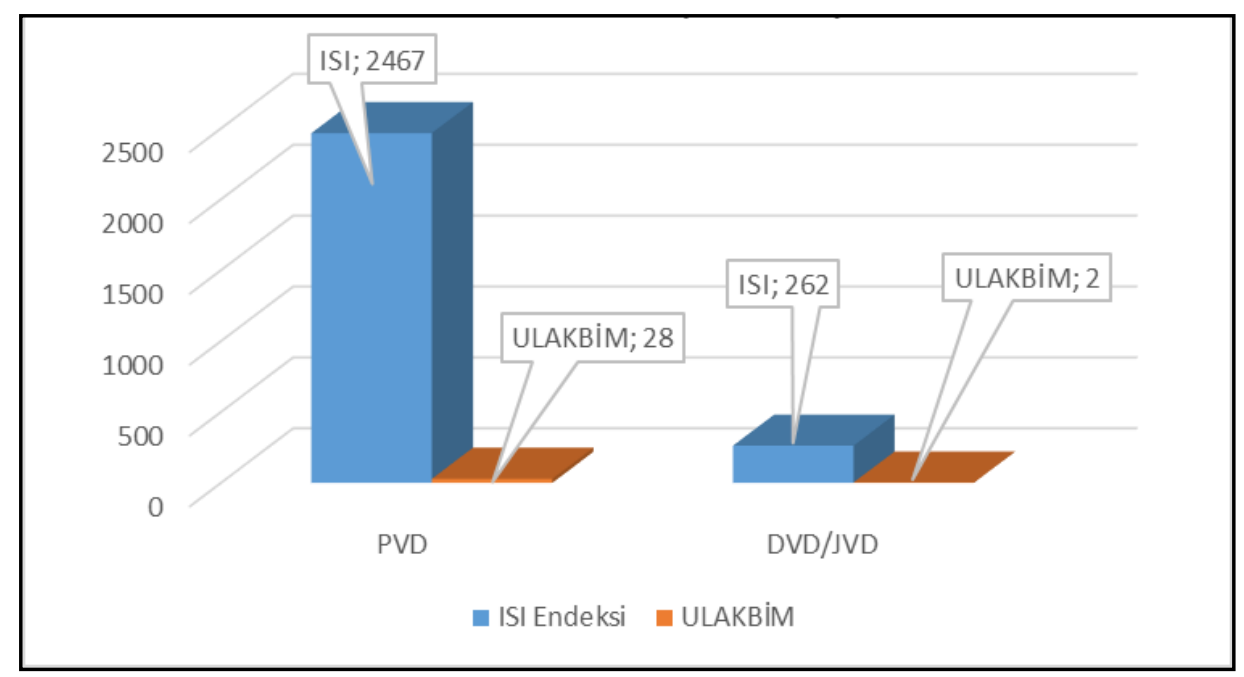

Graph 2. Categorical comparisons of ISI Indexes-ULAKBİM's publication numbers.

\section{Conclusion and Evaluation}

He disadvantages of the PVD system have led to the birth and development of DVD systems. The use of a supersonic gas stream in the DVD system also allows for the mixing of different steam sources to provide a rapid coating with compounds and alloys that are difficult to obtain by other methods (Samtaş and Sert, 2012:30-40). 
Fiziksel Buhar Biriktirme Yöntemlerinden PVD ve JVD/DVD İnce Film

Kaplamaların Karşılaştırılması ve DVD Kaplama Teknolojisinin Endüstriyel

Uygulamaları Üzerine Kavramsal, Akademik ve Teorik Bir Analiz

With the DVD method, different types of coatings can be made at the same time with different surfaces in a complex structure. This system, which is completely computer controlled, can be applied differently without loss of time. It is seen that the processing speed is increased and the transaction cost is reduced considerably in DVD systems. The major advantages of DVD systems over other conventional coating methods can be summarized as follows:

- Highly efficient deposition rate: The interaction between the vapor and the gas jet can be effectively directed to the desired region $(>10 \mu \mathrm{m}$ min-1).

- Deposition on complex surfaces: The gas jet helps the atoms of the vapor to reach the inner parts of the material to be coated, making it possible to coat parts with complex surfaces.

- Controlled mixing of multiple steam sources: Electron beam scanning $(100 \mathrm{kHz})$ using high frequency provides the same evaporation from multiple sources. The interactions of the atoms vaporized by the gas jet allow the creation of new compounds in a controlled manner.

- Low process cost: Efficiently and rapidly controlled use of efficiently stored and directed steam reduces transaction costs considerably (Groves etc., 2000:1-13).

As a result, unlike conventional coating systems, the DVD III system makes it possible to coat different coatings very quickly and cost-effectively even on complex surfaces. It is inevitable to use third-generation DVD coating technologies in industrial applications that completely remove the disadvantages of PVD coating systems. However, in our country there is no investment in this matter, and it is not possible to mention sufficient knowledge about DVD technologies. Given the advantages of DVD systems, it is inevitable to use it especially in the aerospace industry where high-tech products are used. The 
distance that our country carries out in the production of high-tech products is a remarkable level. As coating technologies are thought to be the most effective way to reach superior materials, in addition to PVD systems, it is absolutely necessary to invest in DVD systems. Thus, the improvement in this area is considered to be a significant contribution.

\section{Kaynakça}

\section{Kitaplar}

Axen, N., Hogmark, S., Jacobson, S., Larsson, M., Wiklund, U. (2000). Modern triboloji handbook. Bhushan, B., CRC Pres, Chapters: $13,19,26$.

Bunshatta R.F. (1980). High rate physical vapour deposition processes. Agard Lecture Series No: 106, Material Coating Techniques, Hardford House, London, s:21-26.

Holmberg, K., Matthews, A. (1994). Coatings tribology. Elsevier Tribology Series 28, Elsevier Science, Amsterdam, 11-21, 172-189, 351-371.

Hubler, G. K. (1994) in Pulsed Laser Deposition of Thin Films, ed. D. B. Chrisey and G. K. Hubler. Wiley, New York, 327.

\section{Tezler}

Groves, J.F., Mattausch, G., Morgner, H., Hass, D.D., Wadley, H.N.G. (2000). Directed vapor deposition: low vacuum materials processing technology. Report, University of Virginia, OMB No:0704-0188, 1-13. 
Fiziksel Buhar Biriktirme Yöntemlerinden PVD ve JVD/DVD İnce Film

Kaplamaların Karşılaştırılması ve DVD Kaplama Teknolojisinin Endüstriyel

Uygulamaları Üzerine Kavramsal, Akademik ve Teorik Bir Analiz

\section{Makaleler}

Aytaç, A., İlivan, M., Gül, F. (2016). The effect of TiN and CrN coating on the abrasive wear behavior of cold-work tool steels. Journal of the Balkan Tribological Association, 1:22 (3A-1):3254-3269.

Groves, J.F., Wadley, H.N.G. (1997). Functionally graded materials synthesis via low vacuum directed vapor deposition. Composites Part B 28B:57-69.

Hass, D.D., Groves J.F., Wadley, H.N.G. (2001). Reactive vapor deposition of metal oxide coatings. Surface and Coatings Technology, 146 - 147: 85-93.

Huang, J.H., Hsu, C.Y., Chen S.S., ve Yu, G.P. (2003). Effect of substrate bias on the structure and properties of 1on-plated $\mathrm{ZrN}$ on $\mathrm{Si}$ and stainless steel substrates. Mater. Chem. Phys., 77:7-14.

Kusano, E., Kitagawa, M., Kuroda, Y., Nanto, H., Kinbara, A. (1998). Adhesion and hardness of compositionally gradient $\mathrm{TiO} 2 / \mathrm{Ti} / \mathrm{TiN}, \mathrm{ZrO} 2 / \mathrm{Zr} / / \mathrm{ZrN}$ and TiO2/Ti/Zr/ZrN coatings. Thin Solid Films, 334:151-155.

Samtaş, G., Sert, H. (2012). Doğrudan buhar biriktirme tekniği (DVD). SDÜ Teknik Bilimler Dergisi, 2 (4):30-40.

Schmitz B. (2001) Development of Zn-Mg alloy coatings by JVD. Materials Technology, 72 (11-12):522-527 DOI: 10.1002/srin.200100162.

Schmitz, B., Colin, R. ve Economopoulos, M. (2000). Jet Vapor Deposition, a Novel Vacuum Coating Technique With Superior Properties. Rev. Met. Paris, 97(7-8): 971-978, DOI: 10.1051/metal/200097070971.

Yu Z., Hass D., ve Wadley H.N.G. (2005) NiAl bond coats made by a DVD approach. Materials Science and Engineering, A 394:43-52. 


\section{Bildiriler}

Kıyak, M., Çakır, O., Altan, E. (2003). CVD ve PVD kaplama yöntemlerinin kesici takımlara uygulanması. II. Makina Tasarım ve Imalat Teknolojileri Kongresi (MATIT 2003)., Konya, s:115-124.

\section{Web Siteleri}

DVD Aplications. 13 Mart 2018'de http://directedvapor.com/applications-2/ adresinden erişim sağlanmıştır.

PVD Technology and Coating Portfolio. 19 Şubat 2018'de http://www.ionbond.com/coating-services/forming-molding-tools/coatingportfolio/ adresinden erişim sağlanmıştır. 